\title{
Clinical history in management of suspected syncope: A powerful diagnostic tool
}

\author{
Richard Sutton ${ }^{1}$, Nynke van Dijk ${ }^{2}$, Wouter Wieling ${ }^{3}$ \\ ${ }^{1}$ National Heart and Lung Institute, Imperial College, London, United Kingdom \\ ${ }^{2}$ Department of Family Medicine, Academic Medical Centre, University of Amsterdam, the Netherlands \\ ${ }^{3}$ Internal Medicine, Academic Medical Centre, University of Amsterdam, the Netherlands
}

\begin{abstract}
In this paper, the role of history taking as a diagnostic tool in patients with transient loss of consciousness (TLOC) is addressed. From a literature review it can be demonstrated that, if properly performed, the history is a powerful diagnostic tool, which in the majority of cases proves to be the only 'test' necessary to establish a diagnosis other than physical examination and electrocardiogram in patients with TLOC. In order to substantiate this conclusion, we examine the different levels of history taking according to the skills and training of the physician involved, the diagnostic yield of each level, the methodology, and the influence of the venue and urgency of the case. (Cardiol J 2014; 21, 6: 651-657)
\end{abstract}

Key words: transient loss of consciousness, syncope, diagnosis, risk stratification, narrative medicine, evidence based medicine, decision rules, diagnostic scores

\section{Introduction}

Transient loss of consciousness (TLOC) is a common condition that can be caused by many different disorders with varying clinical consequences ranging from fully benign to potentially lethal. This necessitates an accurate and efficient diagnostic work-up [1].

The aims of the initial diagnostic workup of patients with TLOC are:

- To identify the specific cause of the episode(s) of loss of consciousness in order to apply effective treatment based on the mechanism of the attack. Defining the mechanism is the prerequisite for explaining the episode to a worried patient and for finding a specific therapy to prevent recurrences;

- To assess the prognostic risk, including death, severe adverse events and syncope recurrence if no specific cause can be obtained.

The 2009 Guidelines on Syncope of the European Society of Cardiology (ESC) recommend that the initial work-up of suspected syncope consists of history taking, a physical examination and electrocardiogram (ECG) [1]. However, details of history taking are not given in these guidelines.

In a recent viewpoint [2], we discussed the concept of expert history taking as a diagnostic test in patients with unexplained syncope. We articulated the skills required in a syncope specialist with the aim to guide development and training of those interested in this field.

The focus of the present review is on specific aspects of medical history taking that are important in the evaluation of patients with TLOC. We will pay special attention to history taking in cardiology practice.

We will address:

- The diagnostic yield of history taking in patients with suspected syncope;

- Medical history taking and the assessment of risk for a cardiac cause of syncope;

- Methodological aspects of medical history taking in patients with suspected syncope;

Address for correspondence: Richard Sutton, MB, DSc, 9 Avenue d'Ostende, Monte Carlo, Monaco, MC98000, tel/fax: +33629168389, e-mail: r.sutton@imperial.ac.uk

Received: 19.10.2014 Accepted: 26.10.2014 
- Emergency Department (ED) vs. clinic/office evaluation.

\section{The diagnostic yield of history taking in patients with suspected syncope}

The data from the medical history of patients with TLOC can be obtained in different ways. The following classification can be made.

\section{Obtaining the historical information by questionnaires}

Obtaining information by questionnaires is not as simple as it seems. There is a substantial difference between questionnaires filled in by the patient alone and questionnaires filled in by the patient with the help of a nurse/nurse practitioner. Also, the wording and framing of the questions has a large influence on the answers given [3]. Questionnaires are useful for orientation of the patient to the interview with the physician. Questionnaires also have value as a checklist for a physician to make sure nothing important has been missed. That is the way an airline pilot works before taking off and even for an expert this has value. An important disadvantage of questionnaires is that by separating the story of the patient into different questions, the overall picture of the episodes might be lost.

\section{Information obtained by non-expert} attending physicians taking a medical history

Attending physicians can use a set of questions according to ESC Guidelines [1, 4]. Key elements can be inserted into a decision rule for diagnosing and probably more importantly for risk stratification in emergency settings [5]. Both the knowledge on syncope and the general ability of attending physicians in taking a history probably varies widely and could have a large influence on the diagnostic value.

\section{History taking by a TLOC expert}

In order to make the correct diagnosis and institute effective management, complex syncope patients may need the developed judgment skills of an experienced syncope doctor, yet just experience is not enough to become an expert [6]. An experienced syncope doctor becomes an expert by continuous learning through clinical practice, by reflection and self-criticism, by reading to maintain a deep knowledge in their specialty and by listening to other experts (deliberate practice) [6].

We define a TLOC expert as a clinician:
- With prolonged and intense experience with patients with TLOC through deliberate practice;

- Who is consistently able to exhibit superior performance in the management of patients with TLOC.

Very different diagnostic yields are reported for history taking. Population-based studies performed in 1980's and 1990's in the United States indicate that history, physical examination and ECG together identify a certain or suspected cause of TLOC in $32-74 \%$ of the patients. Studies from Europe in the early 2000's show an even wider range of diagnostic yield (22-98\%) for the initial diagnostic evaluation of patients with TLOC [7].

The great range in diagnostic yield of the medical history in patients with TLOC in these studies can be explained by application of different diagnostic criteria for vasovagal syncope. Using very stringent criteria to diagnose this common condition, i.e. reserving this diagnosis for episodes elicited by a clear-cut precipitating emotional event such as fear, severe pain, minor injury or instrumentation, and evident prodromal symptoms and signs results in a lower diagnostic yield of the medical history, but presumably zero false positive diagnoses. For instance, in an often cited study by Alboni et al. [8], with very stringent diagnostic criteria for reflex syncope, the yield of the medical history was only $14 \%$ for typical vasovagal and $12 \%$ for situational syncope. Fifty percent of the patients were diagnosed with tilt-induced (atypical) vasovagal syncope [8]. Acknowledging the fact that not only emotion but many stresses and conditions that affect (orthostatic) blood pressure regulation can be involved in (vasovagal) reflex syncope [9, $10]$, the diagnostic yield of the medical history will be considerably higher (38-64\%), not affecting the diagnostic accuracy greatly [4, 7]. Importantly, in the study by Alboni et al. [8], triggers in the patients with typical vasovagal syncope, such as high ambient temperature, confined spaces or crowding, fatigue and the postprandial period occurred equally frequent (superimposable percentages) in patients with tilt-induced/atypical syncope. In another study, in consecutive tilt positive patients with unexplained syncope using stringent diagnostic criteria from the history similar triggers were identified with the use of a questionnaire filled in after the tilt table test. Only $11 \%$ of the patients were unable to identify any specific precipitants for their attacks [11]. The triggers in the studies by Alboni et al. [8] and Graham et al. [11] are remarkably similar to those reported by medical students. 


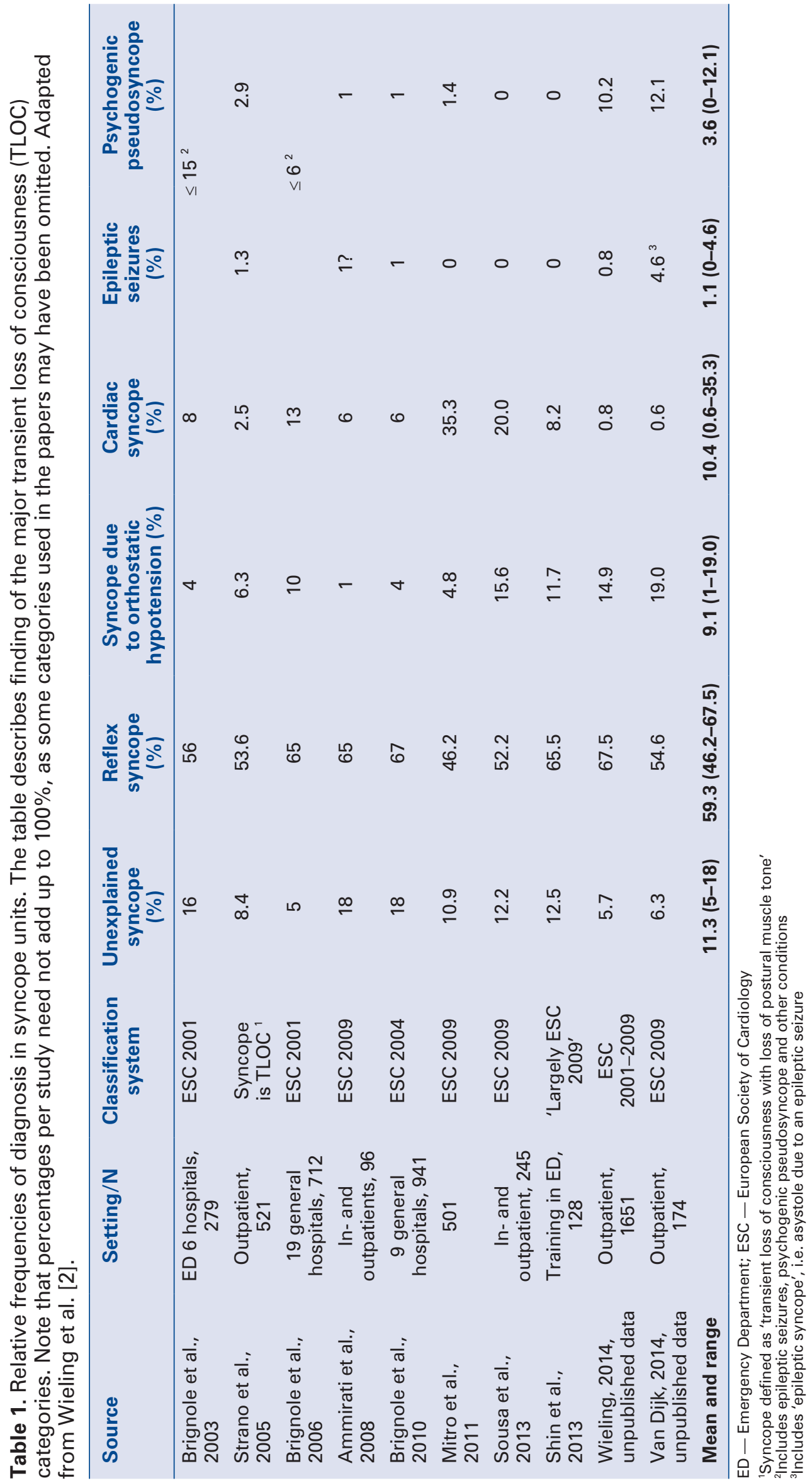


Syncope units have begun to be organized in the last 10 years. The diagnostic yield of patients presenting to these units is high (85-95\%) [13-21]. Table 1 shows rates of diagnoses for various syncope units. With a value around 50\% reflex syncope is by far the most common diagnosis. The rates of other causes of TLOC and of syncope vary considerably, probably largely explained by the setting (inpatient vs. outpatient, referral from ED vs. secondary or tertiary settings) and differences in diagnostic criteria. In the study with the highest diagnostic yield (98\%), a category likely vasovagal (non-classical after exclusion of other causes and absence of heart disease) (11\%) and a category single/rare syncope; no heart disease $(6 \%)$ was used [15].

In the standardized care syncope evaluation studies by Brignole et al. [15, 16], the diagnostic pathway is guided by trained/experienced clinicians not seeing the patients themselves. This is an interesting approach, but very different from expert history taking in complex patients with unexplained syncope. The diagnostic yield of expert history taking in complex patients needs to be quantified in future studies.

\section{Medical history taking and the assessment of risk of cardiac cause of syncope}

Risk stratification is a very important aspect of the evaluation of a patient with syncope. A crucial task for a clinician seeing a patient with suspected syncope is identifying whether a cardiac cause could be present. Criteria from the medical history to identify cardiac syncope have been published [7, 22] and reviewed [5].

The presentation of syncope in the population is bimodal with peak in teenagers and young subjects and a second peak in old age [1]. Age dependent diagnostic scores for identifying cardiac causes are not available, whereas there are major differences in these two age groups, which a cardiologist has to address.

1. Younger subjects:

- Reflex syncope is extremely common in young subjects with a prevalence of about $30 \%[1,12]$. Even in younger patients with, for instance, a long QT or Brugada ECG pattern and syncope because of the very high prevalence of reflex syncope this diagnosis needs to be considered [23-25].

- In young subjects with unexplained syncope and no history of cardiac disease, family history of sudden death, supine syncope or syncope during sleep or exercise, unusual triggers, and a normal ECG and echocardiogram, the chance of cardiac syncope is very low. Sudden cardiac death rates in subjects $<35$ years amount to $1-3 / 100,000$ [26].

2. Older subjects: In contrast, cardiac causes of syncope in the older patient increase progressively with increasing age and, therefore, are an important consideration in every case [27].

\section{Methodological aspects}

A significant challenge in studying history taking as a diagnostic test in patients with TLOC is that no independent reference standard to diagnose syncope is available [2]. Assessing the efficacy of the history as a diagnostic test, therefore, has aspects of circular reasoning. One accepted solution to this problem is to use long-term follow-up as a test of reliability of the diagnoses, relying on ancillary testing and/or additional information during follow-up on recurrences and health-status when possible with the use of an expert review committee [3, 4, 28, 29]. Recruiting patients evaluated by attending physicians from different clinical settings is important in studies assessing the diagnostic yield of history taking in patients with TLOC [3, 4]. However, in many studies assessing the diagnostic yield of history taking, one clinical setting has been assessed and experts have been used to diagnose the patients using questionnaires not examining the patients themselves $[8,15,16]$.

Finally, using medical history taking as a diagnostic test, the summation of all episodes of syncope should be considered and not just the last episode, as is done in some studies [8]. This is an important issue, since in a patient with "classical" vasovagal syncope and, for instance 4 episodes of syncope in our experience, 2 are likely to be classical, 1 is somewhat classic and 1 is atypical. That is typical for vasovagal syncope.

Only 1 study, including two of the authors of this paper (NvD and $\mathrm{WW}$ ), has used this approach. It compared the difference in diagnostic yield of history taking by attending physicians and a TLOC expert using a dedicated long-term follow-up period of at least 2 years, all available tests results and a review committee as a standard of reference [3, 4]. In that study, 503 consecutive patients with TLOC referred to ED, cardiac first aid, neurology, cardiology, internal medicine outpatient departments of a university hospital were 
evaluated by attending physicians with a set of questions according to ESC Guidelines. If TLOC remained unexplained, the patients were referred for a full cardiologic evaluation. If the diagnosis still remained unexplained, patients were then referred to the syncope unit of the university hospital for evaluation by an expert (WW).

The yield of the initial evaluation by the attending physicians was high with 119/503 (24\%) certain and 199/503 (39\%) highly likely (> 80\% certain) diagnoses. The diagnostic yield was higher $(68 \%)$ in the younger ( $<60$ years) patient age group than in the older age group (54\%). The diagnostic yield of the sum of certain and highly likely initial diagnoses ranged from $50 \%$ to $80 \%$ among the 5 participating departments. The overall diagnostic accuracy of the initial evaluation was also high at 91\%. Dangerous diagnoses were not missed [4].

Of the 185 patients without a diagnosis after the initial evaluation, 135 (73\%) received a diagnosis during subsequent testing or follow-up. Thus in total, a diagnosis was obtained in $91 \%$ of the patients. Twenty-seven of 135 (20\%) of the additional diagnoses were obtained by cardiac evaluation including placement of an implantable electrocardiographic loop recorder and/or long-term follow-up.

In 108/135 (80\%) of the patients, the additional diagnosis was obtained by expert history taking and cardiovascular reflex testing (standing up, tilt table testing, carotid sinus massage). Expert history taking, focusing on physiological triggers and predisposing factors that can elicit reflex syncope, was the key in almost all of these 108 patients, while also 9 of the patients were diagnosed as having psychogenic pseudosyncope from the history. Thus in this study, expert history taking was a very powerful diagnostic test in patients with unexplained TLOC after the initial evaluation.

Identifying the situational triggers or predisposing factor is the key to diagnosing "this is very likely reflex syncope". Symptoms and signs are of great importance also, but frequently more difficult to establish from the examination and often even absent, especially in elderly subjects $[8,30]$. Tables 2 and 3 provide a list of situational triggers and predisposing factors [10].

If one accepts the concept that, when physical examination and ECG are normal, an accurate history suggesting reflex syncope is all that is needed to diagnose the condition, the role of tilt-table testing would then mainly serve to confirm the diagnosis and to explain to the patient the origin of her/his problem, to teach them both to
Table 2. Classification of reflex syncope based on triggers.

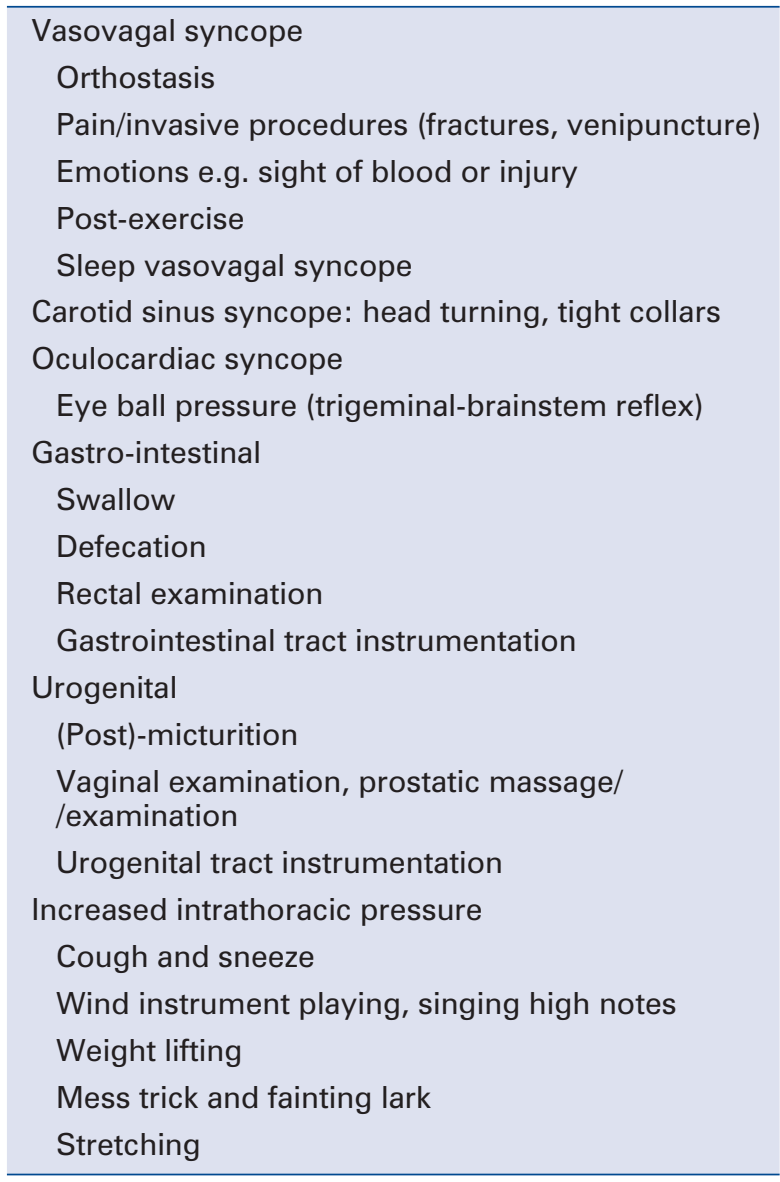

Table 3. Predisposing factors for neurally-mediated syncope.

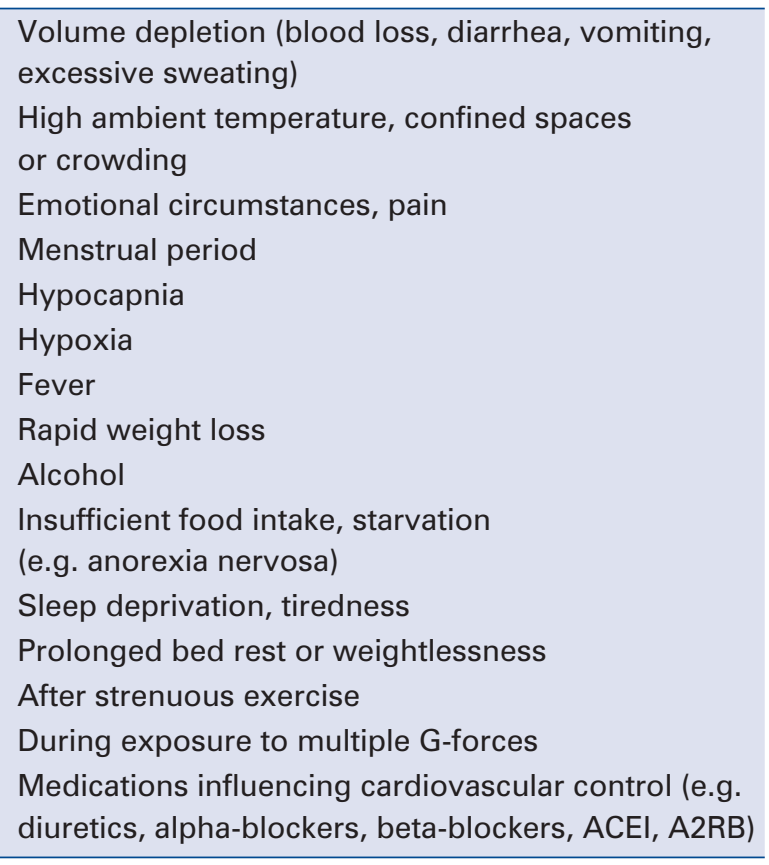

ACEI — angiotensin converting enzyme inhibitors; A2RB - angiotensin receptor blockers 
appreciate premonitory symptoms and the method of physical counter maneuvers that can abort fainting. Using this concept, the problematic low sensitivity, and according to some authors, low specificity of tilt-table testing $[7,31]$ would not be so important. The diagnostic classification of large numbers of patients as "tilt induced/atypical" vasovagal syncope $[8,15,16]$ would be transformed into a classification this is highly likely $(80-100 \%$ probability) reflex syncope. Such a classification is useful to explain to the patient the origin of the fall in blood pressure.

A tilt-table test performed by an expert him/ /herself during an evaluation of a patient with complex unexplained syncope vs. a routine tilt-table test performed by a technician on a separate occasion are different. During a tilt table test performed by an expert as "part of the physical examination" the patient can describe the complaints directly to an expert. In addition, after performing a careful physical examination/tilt table test patients lose their inhibitions on important previously concealed aspects of their history [32].

\section{Differences in approach between ED and office settings}

TLOC risk evaluation in the emergency setting by attending physicians and diagnosing a difficult case of unexplained TLOC by an expert are different "business activities". In a futuristic view on innovation in health care delivery from 'Is there still a role for the Harvard Business School', Christensen et al. [33] define two general types of job-focused business activities: solution shops and value adding process business.

Solution shops are institutions built to diagnose and solve unstructured problems. They deliver through experts who draw upon their intuition and problem solving skill to diagnose the cause of complicated problems and then recommend solutions. Consulting agencies, research and development agencies and law practices are examples of solution shops. The solution shop is a fee for service/consultation activity. Expert evaluation/management of TLOC puzzles in an outpatient office is a typical solution shop activity. Here we communicate as experts in narratives, playing Sherlock Holmes, building a history and making much use of pathophysiology. Evidence Based Medicine likelihood ratios are not so important, although they might be unconsciously applied. The psychosocial setting is taken into account. This is old-fashioned medicine in practice, where experience, intuition and pattern recognition count highly just as for a seasoned car mechanic. We must consider the possibility that, in the future, computer systems could facilitate aspects of the expert process but probably never be the sole means to our end.

Value adding business activities transform inputs of resources - people, material, energy, information into outputs of higher order. Retailing, restaurants and automobile manufacturing are examples. Value-adding processes tend to do their work in a repetitive way. They are not nearly as dependent on instincts of people as is the case with solution shop business. The Toyota production system is the classical example of a value adding business or "focused factory". The focused factory is competitive in an economic world where costs of products are calculated. Examples of focused factories in the medical field in the future could be a pacemaker implantation or ablation factory. TLOC risk classification business can be viewed as a health oriented focused factory/Toyota assembly line with the emergency as a conveyor belt checking patients as cases remaining unseen by doctors. The use of decision rules dealing with risk stratification fits with a group average Evidence Based Medicine approach of checking "products: in a Toyota assembly line. The end products of the assembly line are 'you have'/'you do not have' (by far the majority) a dangerous type of TLOC.

\section{Conclusions}

The medical history in a patient with TLOC can be seen as a diagnostic test with very different test characteristics depending on how and by whom the information from the patient is obtained and analyzed [3, 7]. Guidelines, diagnostic scores and risk rules provide a reasonable and practical approach to care of patients with TLOC by non-experts in general and especially in emergency settings. The differences in the diagnostic yield of history taking by an experienced syncope specialist vs. non-experts using diagnostic scores and the additional value of expert history taking in complex cases need to be quantified in future studies. History taking plays a crucial role in the management of TLOC. Standards for training and experience are needed. Training of a younger generation in the essentials of expert history taking should have high priority. 


\section{Acknowledgements}

We thank Mark Linzer (Boston) and Gert van Dijk (Leiden) for their wisdom applied to this report.

\section{Conflict of interest: None declared}

\section{References}

1. Moya A, Sutton R, Ammirati F et al. Guidelines for the diagnosis and management of syncope (version 2009). Eur Heart J, 2009; 30: 2631-2671.

2. Wieling $\mathrm{W}$, van Dijk N, de Lange FJ et al. History taking as a diagnostic test in patients with syncope: Developing expertise in syncope. Eur Heart J, 2014 [In press].

3. Romme JJ, van Dijk N, Boer KR, Bossuyt PM, Wieling W, Reitsma JB. Diagnosing vasovagal syncope based on quantitative history taking: Validation of the Calgary Syncope Symptom Score. Eur Heart J, 2009; 30: 2888-2289.

4. Van Dijk N, Boer KR, Colman N et al. High diagnostic yield and accuracy of history, physical examination, and ECG in patients with transient loss of consciousness in FAST: The Fainting Assessment study. J Cardiovasc Electrophysiol, 2008; 19: 48-55.

5. Sheldon RS. Syncope diagnostic scores. Prog Cardiovasc Dis, 2013; 55: 390-395.

6. Ericsson KA. An expert-performance perspective of research on medical expertise: The study of clinical performance. Med Educ, 2007; 41: 1124-1130.

7. Colman N, Nahm K, van Dijk JG, Reitsma JB, Wieling W, Kaufmann $\mathrm{H}$. Diagnostic value of history taking in reflex syncope. Clin Autonom Res, 2004; 14 (suppl. 1): 37-44.

8. Alboni P, Brignole M, Menozzi C et al. Clinical spectrum of neutrally mediated reflex syncope. Europace, 2004; 6: 55-62.

9. Wieling W, Thijs RD, van Dijk N, Wilde AA, Benditt DG, van Dijk JG. Symptoms and signs of syncope: A review of the link between physiology and clinical clues. Brain, 2009; 132: 2630-2642.

10. Krediet CTP, Wieling W. Situational syncope. In: Mathias CJ, Bannister R eds. Autonomic failure. $5^{\text {th }}$ Ed. Oxford University Press, Oxford, UK 2013: 730-774.

11. Graham LA, Kenny RA. Clinical characteristics of unexplained syncope and their relationship to tilt table test outcomes. Clin Autonom Res, 2002; 12: 88-93.

12. Ganzeboom KS, Colman N, Reitsma JB, Shen WK, Wieling W. Prevalence and triggers of syncope in medical students. Am J Cardiol, 2003; 91: 1006-1008.

13. Brignole M, Disertori M, Menozzi C et al.; for the Evaluation of Guidelines in Syncope Study Group. Management of syncope referred urgently to general hospitals with and without syncope units. Europace, 2003; 5: 283-291.

14. Strano S, Colosimo C, Sparagna A et al. Multidisciplinary approach for diagnosing syncope: A retrospective study on 521 outpatients. J Neurol Neurosurg Psychiatry, 2005; 76: 1597-1600.

15. Brignole M, Menozzi C, Bartoletti A et al.; for the Evaluation of guidelines in Syncope Study 2 (EGSYS-2) group. A new management of syncope: Prospective systematic guideline-based evaluation of patients referred $t$ urgently to general hospitals. Europace, 2006; 27: 76-82.
16. Brignole M, Ungar A, Bartoletti A et al.; for the Evaluation of Guidelines in Syncope Study 2 (EGSYS-2) Group. Standardized-care pathway vs. usual management of syncope patients presenting as emergencies at general hospitals. Europace, 2006; 8: 644-650.

17. Ammirati F, Colaceci R, Cesario A et al. Management of syncope: Clinical and economic impact of a Syncope Unit. Europace, 2008; 10: 471-476.

18. Brignole M, Ungar A, Casagranda I et al. Syncope Unit Project (SUP) investigators. Prospective multicentre systematic guideline-based management of patients referred to the Syncope Units of general hospitals. Europace, 2010; 12: 109-118.

19. Mitro P, Kirsch P, Valočik G, Murín P. A prospective study of the standardized diagnostic evaluation of syncope. Europace, 2011; 13: 566-577.

20. Sousa P, Marques N, Faria R et al. Syncope unit: Experience of a center using diagnostic flowcharts for syncope of uncertain etiology after initial assessment. Rev Port Cardiol, 2013; 32: 581-91.

21. Shin TG, Kim JS, Song HG, Jo IJ, Sim MS, Park SJ. Standardized approaches to syncope evaluation for reducing hospital admissions and costs in overcrowded emergency departments. Yonsei Med J, 2013; 54: 1110-1118.

22. Berecki-Gisolf J, Sheldon A, Wieling W et al. Identifying cardiac syncope based on clinical history: A literature-based model tested in four independent datasets. PLoS One, 2013; 24: e75255.

23. Colman N Bakker A, Linzer M, ReitsmaJB, Wieling W, Wilde AA M. Value of historytaking in syncope patients: In whom to suspect long QT syndrome? Europace 2009;11:937-943.

24. Olde Nordkamp RA, Vink SA, Wilde AAM et al. Syncope in Brugada syndrome: Prevalence, clinical significance, and clues from history taking to distinguish arrhythmic from non-arrhythmic causes. Heart Rhythm, 2014; DOI: 10.1016/j.hrthm.2014.10.014 (Epub ahead of print).

25. Olde Nordkamp LR, Ruwlad MH, Goldenberg I et al. Syncope in genotype-negative long QT syndrome family members. Am J Cardiol, 2014; DOI: 10.1016/jamjcar.2014.07.044 (Epub ahead of print).

26. Margey R, Roy A, Tobin S et al. Sudden cardiac death in 14- to 35-year olds in Ireland from 2005 to 2007: A retrospective registry. Europace, 2011; 13: 1411-1418.

27. Matthews IG, Tresham IAE, Parry SW. Syncope in the older person. Card Electrophysiol Clin, 2013; 5: 457-467.

28. Reitsma JB, Rutjes AWS, Kkan KS, Coomarasamy A, Bossuyt PM. A review of solutions for diagnostic accuracy: Studies with an imperfect or missing reference standard. J Clin Epidem, 2009; 62: 797-806.

29. Bertens LCM, Broekhuizen BDL, Naaktgeboren CA et al. Use of expert panels to define the reference standard in diagnostic research: A systematic review of published methods and reporting. PLOS Med, 2013; 10: e1001531.

30. Romme JJ, van Dijk N, Boer KR et al. Influence of age and gender on the occurrence and presentation of reflex syncope. Clin Autonom Res, 2008; 18: 127-133.

31. Sutton R, Brignole M. Twenty-eight years of research permit reinterpretation of tilt-testing: hypotensive susceptibility rather than diagnosis. Eur Heart J, 2014; 35: 2211-2212.

32. Fowler PBS. Evidence-based diagnosis. J Evaluation Clin Pract, 1997; 3: 153-159.

33. Christensen CM, Grossman JH, Hwang J. The innovator's prescription. A disruptive solution for health care. McGraw Hill, New York 2009. 